\title{
Vaccination and infection prevention in inflammatory bowel disease
}

\author{
Severine Vermeire*, Gert Van Assche and Paul Rutgeerts
}

\author{
Address: Department of Gastroenterology, University Hospitals Leuven, Herestraat 49 - B3000 Leuven, Belgium \\ *Corresponding author: Severine Vermeire (severine.vermeire@uz.kuleuven.ac.be) \\ Fl000 Medicine Reports 2010, 2:80 (doi:10.3410/M2-80) \\ This is an open-access article distributed under the terms of the Creative Commons Attribution-Non Commercial License \\ (http://creativecommons.org/licenses/by-nc/3.0/legalcode), which permits unrestricted use, distribution, and reproduction in any medium, \\ provided the original work is properly cited. You may not use this work for commercial purposes. \\ The electronic version of this article is the complete one and can be found at: http://f $1000 . c o m / r e p o r t s / m / 2 / 80$
}

\begin{abstract}
The current medical therapy used in Crohn's disease and ulcerative colitis comprises drugs that interfere with immune response and therefore caution is needed for infectious side effects, and where possible, strategies to prevent their occurrence should be undertaken. Last year, international consensus guidelines on this topic were published by the European Crohn's and Colitis Organisation.
\end{abstract}

\section{Introduction and context}

Biological therapies can no longer be disregarded in the management of inflammatory bowel disease (IBD) and have become - together with the 5-aminosalicylates (5-ASAs), methotrexate, and purine analogues (azathioprine and 6-mercaptopurine) - the cornerstone of IBD treatment. Corticosteroids, though abandoned more and more, may still be used as efficacious induction agents or as a bridge to the action of immunomodulators (or as both). Given that the mentioned drugs, with the exception of 5-ASAs, affect the immunity of the patient and that there is increasing use of these drugs in IBD, safety concerns include the occurrence of (opportunistic) infections, and physicians should take active measures to prevent or treat these infections. Moreover, as many patients now enjoy a very good quality of life as a consequence of the therapeutic advances made, travel and vaccination advice become part of the follow-up of patients with IBD. Prevention of opportunistic infection includes recognizing risk factors for infection, closely monitoring patients during therapy (clinical and lab), and vaccinating where possible. Risk factors for opportunistic infections include combined immunomodulator use, including corticosteroids, older age, malnutrition, and comorbidities [1].

\section{Recent advances}

The best-documented infectious complication of antitumor necrosis factor (anti-TNF) agents (infliximab, adalimumab, and certolizumab pegol) is the reactivation of latent tuberculosis (TB). By February 2003, active TB was reported in 350 of more than 400,000 patients treated with infliximab, a cumulative incidence of 0.46 per 1000 patient-years. Most cases will occur within the first 2 months after initiation of therapy and are associated with a substantial rate of mortality. Therefore, all patients who will undergo treatment with an anti-TNF agent should be questioned and evaluated for latent TB with a tuberculin skin test or interferon-gamma release assay and chest X-ray [2]. Treatment of latent TB should be initiated at least 2 weeks prior to therapy. Recommendations for screening $\mathrm{TB}$ and treatment are proposed by national scientific organizations and authorities, and their national guidelines should be consulted by physicians.

The largest long-term study on safety of anti-TNF from clinical practice was done in 743 infliximab-treated IBD patients and an equally sized control group of non-antiTNF-treated IBD patients [3]. With a follow-up of as long as 14 years, concomitant steroid therapy was the only independent risk factor for infections in the infliximab group, with a 2.69 -fold (95\% confidence interval [CI] 1.18-6.12) increased risk in the case of co-administration of corticosteroids together with infliximab $(P=0.018)$. Likewise, a recent cohort study from British Columbia, Canada, showed that corticosteroids tripled the risk of 
Clostridium difficile infections (relative risk 3.4, 95\% CI 1.96.1) compared with other immunosuppressant agents [4].

The European Crohn's and Colitis Organisation (ECCO) consensus on opportunistic infections in IBD brought 30 IBD and infectious disease specialists together. Their guidelines recommend serology testing for specific viruses and administration of a number of vaccinations shortly following the diagnosis of IBD. The reason for doing this at an early stage is that at least half of the patients will require immunomodulators or anti-TNF (or both) during their further disease course and live-attenuated vaccines (yellow fever and varicella being the two most important ones) cannot be administered during this treatment. Second, immunomodulators or biological agents (or both) may attenuate the response to vaccination. Figure 1 summarizes which serologies should be checked and which vaccines are recommended $[2,5]$. Besides the serologies that should be checked (Figure 1), a baseline laboratory exam, including neutrophil, eosinophil, and lymphocyte blood count and C-reactive protein and HIV serology, is recommended.

Nobody questions vaccination for influenza and pneumococcus pneumoniae, however, vaccinating for hepatitis B virus (HBV) and hepatitis $\mathrm{C}$ virus (HCV) has generated debate. In fact, no consensus regarding HCV screening could be made by the experts. More recently, a nationwide Spanish study of more than 2000 consecutively recruited patients with IBD showed, in contrast to previous reports, that the prevalence rates of HBV and HCV infection were similar to those of the general population [6]. This was confirmed in a French study [7]. However, the frequency and severity of liver dysfunction appear to be significantly higher in HBVinfected patients than in HCV-infected patients. In the study from the Spanish GETECCU (Grupo Español de Enfermedades de Crohn y Colitis Ulcerosa), HBV infection in patients with IBD resulted in liver dysfunction in more than one-third (36\%) of patients, including six cases of hepatic failure. Liver dysfunction in HCV was less frequent (15.7\%), and only one patient developed hepatic failure [8]. The treatment with two or more immunosuppressants was an independent predictor of HBV reactivation (odds ratio 8.75, 95\% CI 1.16-65.66). Interestingly, the studies that have reported on the degree of effective vaccination for HBV show that only a minority of the patients with IBD (range $12-48 \%$ ) are effectively vaccinated. We recommend that HBV and HCV serology be checked and that patients negative for $\mathrm{HBV}$ receive vaccination. In

Figure I. Serology and vaccination to be checked and performed before immunomodulators or biological therapy

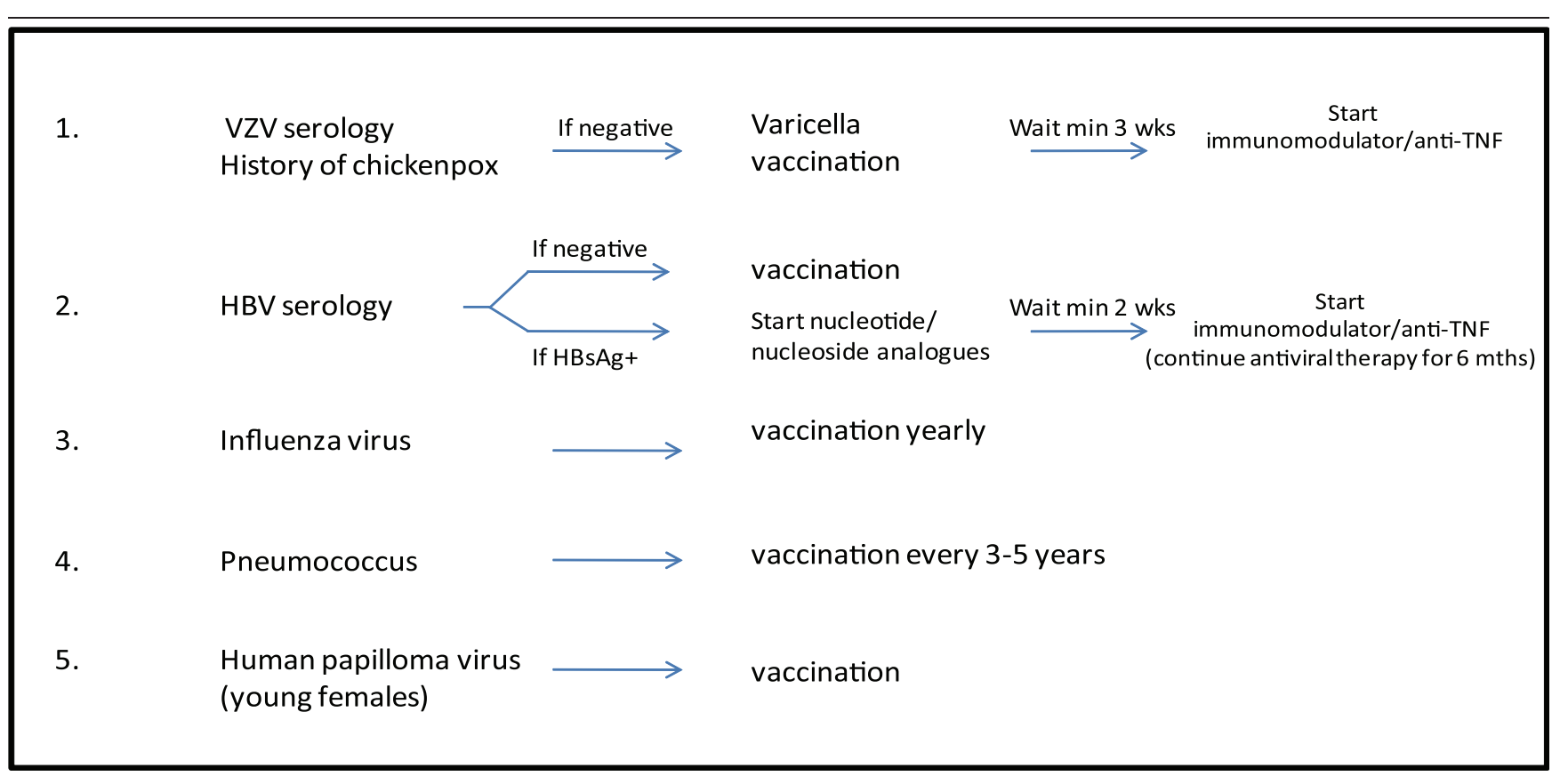

The figure depicts the serology and vaccination to be performed in inflammatory bowel disease patients before immunomodulators or biological therapy (or both) are started, as recommended by the consensus guidelines of the European Crohn's and Colitis Organisation. anti-TNF, anti-tumor necrosis factor; $\mathrm{HBsAg}+$, positive for the surface antigen of $\mathrm{HBV}$; HBV, hepatitis B virus; VZV, varicella zoster virus. 
HCV-positive patients under long-term treatment with immunomodulators or biologicals (or both), aminotransferases and HCV viral load should be followed up.

In comparison with the more severe (opportunistic) infections, benign infections such as the common cold, bronchitis, warts, and herpes are found more frequently. In a prospective cohort study with a follow-up of 207 patient-years, no difference in upper respiratory tract infections was found between azathioprine-taking patients and those not on purine analogues [9]. In contrast, the rates of incidence of herpes flares and warts were significantly increased in IBD patients receiving azathioprine. Where possible, stopping therapy may be recommended if flares are too frequent or severe. If therapy needs to be continued to maintain disease remission, daily oral acyclovir (400 mg twice a day) is an option to prevent frequent recurrences of herpes simplex disease.

\section{Implications for clinical practice}

IBD patients who need immunomodulators or biological therapy should receive appropriate counseling regarding the risk of infections and should receive a number of vaccinations:

- First, all patients starting on an anti-TNF agent should undergo tuberculin skin testing or an interferon-gamma release assay as well as a chest X-ray to rule out latent TB; if the assay is positive, anti-TB treatment should be initiated at least 2 weeks prior to therapy.

- The ECCO consensus guidelines on opportunistic infections furthermore recommend serology testing for varicella zoster virus (VZV) and $\mathrm{HBV}$ and vaccination for varicella (in case of negative serology for VZV and no history of chickenpox), HBV, influenza (yearly), and pneumococcal polysaccharide (every 3-5 years).

- Young females are advised to get human papilloma virus vaccination.

- A baseline laboratory exam, including neutrophil, eosinophil, and lymphocyte blood count, C-reactive protein, and HIV serology, should be performed at the time of diagnosis, and routine blood monitoring every 2-4 months should be continued while the patient is on immunosuppressive agents.

- Mild viral infections like warts and herpes are more frequent under immunomodulators or anti-TNF but, in general, are no reason to stop therapy. If such an infection is too invalidating for the patient, daily oral acyclovir (400 mg twice a day) is an option in case of herpes simplex disease.

\section{Abbreviations}

5-ASA, 5-aminosalicylate; anti-TNF, anti-tumor necrosis factor; CI, confidence interval; ECCO, European Crohn's and Colitis Organisation; HBV, hepatitis B virus; HCV, hepatitis $\mathrm{C}$ virus; IBD, inflammatory bowel disease; $\mathrm{TB}$, tuberculosis; VZV, varicella zoster virus.

\section{Competing interests}

The authors declare that they have no competing interests.

\section{References}

I. Toruner M, Loftus EV Jr, Harmsen WS, Zinsmeister AR, Orenstein R, Sandborn WJ, Colombel JF, Egan LJ: Risk factors for opportunistic infections in patients with inflammatory bowel disease. Gastroenterology 2008, 134:929-36.

FI000 Factor 9

Evaluated by Paul Pavli 22 Apr 2008, Klaus Monkemuller I3 Jan 2009

2. Rahier JF, Ben-Horin S, Chowers Y, Conlon C, De Munter P, D'Haens G, Domènech E, Eliakim R, Eser A, Frater J, Gassull M, Giladi M, Kaser A, Lémann M, Moreels T, Moschen A, Pollok R, Reinisch W, Schunter M, Stange EF, Tilg H, Van Assche G, Viget N, Vucelic B, Walsh A, Weiss G, Yazdanpanah Y, Zabana Y, Travis SPL, Colombel JF; European Crohn's and Colitis Organisation (ECCO): European evidence-based Consensus on the prevention, diagnosis and management of opportunistic infections in inflammatory bowel disease. J Crohn's Colitis 2009, 3:47-91.

3. Fidder H, Schnitzler F, Ferrante M, Noman M, Katsanos K, Segaert S, Henckaerts L, Van Assche G, Vermeire S, Rutgeerts P: Long-term safety of infliximab for the treatment of inflammatory bowel disease: a single-centre cohort study. Gut 2009, 58:50I-8.

4. Schneeweiss S, Korzenik J, Solomon DH, Canning C, Lee J, Bressler B: Infliximab and other immunomodulating drugs in patients with inflammatory bowel disease and the risk of serious bacterial infections. Aliment Pharmacol Ther 2009, 30:253-64.

5. Rahier JF, Yazdanpanah Y, Colombel JF, Travis S: The European (ECCO) Consensus on infection in IBD: what does it change for the clinician? Gut 2009, 58:|3|3-5.

6. Loras C, Saro C, Gonzalez-Huix F, Mínguez M, Merino O, Gisbert JP, Barrio J, Bernal A, Gutiérrez A, Piqueras M, Calvet $X$, Andreu M, Abad A, Ginard D, Bujanda L, Panés J, Torres M, Fernández-Bañares F, Viver JM, Esteve M; GETECCU (Grupo Español de Enfermedades de Crohn y Colitis Ulcerosa): Prevalence and factors related to hepatitis $\mathbf{B}$ and $\mathbf{C}$ in inflammatory bowel disease patients in Spain: a nationwide, multicenter study. Am J Gastroenterol 2009, 1 04:57-63.

7. Chevaux JB, Nani A, Oussalah A, Venard V, Bensenane M, Belle A, Gueant JL, Bigard MA, Bronowicki JP, Peyrin-Biroulet L: Prevalence of hepatitis $B$ and $C$ and risk factors for nonvaccination in inflammatory bowel disease patients in Northeast France. Inflamm Bowel Dis 2010, 16:916-24.

8. Loras C, Gisbert JP, Mínguez M, Merino O, Bujanda L, Saro C, Domenech E, Barrio J, Andreu M, Ordás I, Vida L, Bastida G, González-Huix F, Piqueras M, Ginard D, Calvet X, Gutiérrez A, Abad A, Torres M, Panés J, Chaparro M, Pascual I, RodriguezCarballeira M, Fernández-Bañares F, Viver JM, Esteve M; REPENTINA study; GETECCU (Grupo Español de Enfermedades de Crohn y Colitis Ulcerosa) Group: Liver dysfunction related to hepatitis B and $C$ in patients with inflammatory bowel disease treated with immunosuppressive therapy. Gut 2010, 59:1340-6.

9. Seksik P, Cosnes J, Sokol H, Nion-Larmurier I, Gendre JP, Beaugerie L: Incidence of benign upper respiratory tract infections, HSV and HPV cutaneous infections in inflammatory bowel disease patients treated with azathioprine. Aliment Pharmacol Ther 2009, 29: I 106-13. 